\title{
BMJ Open What are parents' perceptions related to barriers in diagnosing swallowing dysfunction in children? A grounded theory approach
}

\author{
Abdulsalam Baqays (D) , ${ }^{1,2}$ Marghalara Rashid, ${ }^{3}$ Wendy Johannsen, ${ }^{4}$ Hadi Seikaly, ${ }^{2}$ \\ Hamdy El-Hakim ${ }^{2}$
}

To cite: Baqays A, Rashid M, Johannsen W, et al. What are parents' perceptions related to barriers in diagnosing swallowing dysfunction in children? A grounded theory approach. BMJ Open 2021;11:e041591. doi:10.1136/ bmjopen-2020-041591

- Prepublication history and supplemental material for this paper is available online. To view these files, please visit the journal online (http://dx.doi org/10.1136/bmjopen-2020041591).

Received 12 June 2020 Revised 22 February 2021 Accepted 23 February 2021

Check for updates

(c) Author(s) (or their employer(s)) 2021. Re-use permitted under CC BY-NC. No commercial re-use. See rights and permissions. Published by BMJ.

${ }^{1}$ Otolaryngology, Head \& Neck Surgery, King Saud University College of Medicine, Riyadh, Saudi Arabia

${ }^{2}$ Otolaryngology, Head \& Neck Surgery, University of Alberta, Edmonton, Alberta, Canada ${ }^{3}$ Pediatric, University of Alberta, Edmonton, Alberta, Canada ${ }^{4}$ Speech-Language pathology, Stollery Children's Hospital, Edmonton, Alberta, Canada

Correspondence to Professor Hamdy El-Hakim; hamdy.elhakim@albertahealt hservices.ca

\section{ABSTRACT}

Objectives Swallowing dysfunction (SwD) is underreported in otherwise healthy infants and toddlers (OHITs). The identification of parental perceptions of factors that may hinder the diagnosis could help clinicians manage these children in a more expeditious manner. This study investigated the barriers to diagnosing SwD, as reported by the families.

Design Grounded theory study.

Setting This study was performed in a tertiary care paediatric centre in Canada.

Participants Parents of OHITs were recruited using purposeful sampling.

Intervention We used detailed, semistructured, in-person interviews and the audiotapes and transcriptions were thematically analysed. From the parental insights, we built a framework composed of three themes of barriers. Result Ten parents of OHITs with SwD were interviewed. The children presented with recurrent coughing, choking, cold-like symptoms, recurring/consistent illnesses and feeding difficulties. They were managed with multiple rounds of antibiotics and diagnosed with allergies, asthma or recurrent viral infections before considering SwD. The three emerging themes are false beliefs about SwD among parents and some physicians, parent-related barriers and physician-related barriers. These barriers had severely impacted the parents, impairing work productivity and leading to work-related reprimands and changes in the family dynamics.

Conclusion This study suggests that there are several barriers that face the parents of OHITs when seeking a diagnosis of SwD and initiating appropriate management. These barriers likely interact with one another and amplify their effects on the family and the child. A common denominator is a lack of education regarding SwD, its clinical manifestations and the available expertise to manage this condition.

\section{INTRODUCTION}

Dysphagia is a common condition that affects children. Bhattacharyya analysed data collected from the national health survey and estimated that approximately half a million children are affected by dysphagia annually in the USA. ${ }^{1}$ Despite the methodological shortcomings of that report, it provided an important indicator
Strengths and limitations of this study

- As paediatric swallowing dysfunction is underreported, this study tried to get the parents' perspective in experience to understand the reason behind it.

- Data obtained through an hour-long of a semistructured interview with each participant, which transcribed verbatim and verified by the participants.

- The result was verified by another group of participants to certify the experience.

- This was a single care centre study and might not be generalised on other cohorts as the included participants were parents of otherwise healthy infants and toddlers with swallowing dysfunction, who were from the province of Alberta in Canada.

- Using a purposeful sampling technique provided rich data to understand the barriers to detecting swallowing dysfunction in our cohort of interest; however, it constrains the generalisation to other cohorts.

of the burden of this condition. Dysphagia is especially frequent in children of certain highrisk populations, such as those with neurological, genetic and anatomical defects, reaching $85 \%$ in some. ${ }^{23}$ Oropharyngeal dysphagia, also known as swallowing dysfunction (SwD), has been increasingly studied in the otolaryngological field. Our interest has focused on otherwise healthy infants and toddlers (OHITs), that is, those aged 2 years or younger who have no neurological or syndromic diagnosis. We believe this cohort is an understudied and underrepresented population. Our literature search revealed that SwD affects between $13.35 \%$ and $74.85 \%$ of the OHIT cohort in relevant reports, ${ }^{4-8}$ despite the absence of well-designed epidemiological studies. This is partly due to the absence of a valid screening test.

A diagnosis of SwD is established by videofluoroscopic swallowing studies (VFSS) and functional endoscopic evaluation of swallowing (FEES). ${ }^{9} 10$ Although these are the 
reference standard tests for $\mathrm{SwD}$, they inherently suffer from important drawbacks. These include radiation exposure, the requirement for experienced personnel with specialised training, and the intrusiveness and discomfort of the process itself. ${ }^{11}$ Alternative tools have been sought, for example, ultrasonography, auscultation, but none have been proven accurate or valid for regular clinical utility. Patient-reported outcomes (PROs) have recently been demonstrated to have clinical utility to replace or supplement traditional endpoints (such as in osteoarthritis) and satisfy the interests of the patients or proxy. ${ }^{12} 13$

We designed a mixed-method research project to develop and validate a PRO tool for SwD in OHITs. A common narrative consistently emerged during the initial qualitative phase and while interviewing the parents. This narrative expresses a negative experience while achieving the diagnosis.

There are some reports on the experiences of parents of children with dysphagia and feeding problems in the literature. Hewetson and Singh published a phenomenological report that described the lived experiences of seven parents who had children (mean age 80 months, range 36-156 months) with feeding and swallowing problems. ${ }^{14}$ They reported that these parents endured two independent journeys. The first was the journey of deconstruction; here the parents faced dissipating life dreams, a continuum of life changes and a constant feeling of powerlessness. In the second journey, reconstruction, the parents approached life more realistically and became proactive information seekers to empower themselves.

Lutz undertook a study to comprehend the experiences of parents of neonatal and paediatric intensive care unit graduates with feeding problems using a convenience sample of 15 parents and ten healthcare providers. ${ }^{15}$ The salient themes identified through content analysis were: (1) diverse and fluctuating parental responses; (2) feeding as the focus; (3) isolation and disappointed expectations; (4) conflicting collaboration, perceptions and communication; and (5) barriers and challenges to accessing care.

However, none of these reports addressed the experiences of the parents of OHITs who were not yet diagnosed with $\mathrm{SwD}$. They were based on experiences of high-risk populations (such as Down syndrome ${ }^{16}$ ) who already had been diagnosed with dysphagia and feeding problems ${ }^{17}$ and who were enrolled in special feeding programmes.

Here, we report our findings that point to barriers to the diagnosis of SwD in OHITs.

\section{METHOD}

The grounded theory was chosen as an overarching theoretical approach because we sought an exploratory theory that was environmentally sensitive to the social processes and would assist in understanding their relations. ${ }^{18}{ }^{19}$ Purposeful sampling was used to obtain rich data that contained parental insights into their children's experience. We included parents of OHITs who were not diagnosed with named syndromes, neurological or genetic disorders, or exhibited dysmorphic features. The parents were identified from the database of the multidisciplinary Aspiration and Aerodigestive Clinic at the Stollery Children's Hospital at the recommendation of the treating speech-language pathologist based on the parents' potential willingness to participate in such a study, and their comprehension of English language. A semi-structured interview was selected for data collection.

Twenty-one eligible parents were identified and approached to query participation in the study. Eighteen of them agreed, whereas three of them declined due to conflict of data collection time with other commitments related to personal or work-related reasons. After an initial approach to solicit participation, written informed consent was obtained from each participant after one of the investigators explained the aims, related potential risks and the benefits. A second consent was obtained from the participants who were willing to provide helpful related material (eg, videos, blogs and pictures). Also, the anonymity of the participants was maintained throughout the study phases by using unique identifying numbers.

A guideline was designed to navigate the interview. This guideline contained eight open-ended questions (online supplemental file 1). It was built through a multistep process that started with a literature search for validated questionnaires designed to assess swallowing in children. Based on the literature, commonly used questions were compiled to formulate the first draft. This draft was honed in a meeting session by two paediatric experts, an otolaryngologist and a speech-language pathologist; these individuals led the multidisciplinary clinic. The draft interview guideline was further refined and revised with the help of a panel of independent qualitative method experts over another meeting session.

This interview guide was flexibly used during the interviews. A prompting technique was used to explore fuzzy information expressed by the participants in addition to active listening (ie, summarising and restating what the participant had said). These interviews were performed by a single interviewer and ranged from $45 \mathrm{~min}$ to 1 hour and were audiorecorded and transcribed verbatim. Interviewees had no previous encounter with the interviewer. Other than the interviewer and the interviewee, no other participants attended the interview. The interviewer was a recent graduate of Medicine who received 2 years clinical experience in the field of Otolaryngology-Head and Neck surgery and was completing his postgraduate degree. Also, he was trained by an expert in Qualitative Research on techniques of performing a proper interview. The interviewer introduced himself to the parents as a master's degree candidate who had no role or influence on the management of their children.

Once the investigators noted the emergence of a consistent experience of obstacles to establishing a diagnosis and its impact on the life of the parents and children, this information was further analysed. 
We employed the six-step thematic analysis technique proposed by Braun and Clerk. ${ }^{20}$ This technique was a sequential process that included data familiarisation, the production of codes and the generation, reviewing, defining and naming of themes. The research team members started to familiarise themselves with the data by repeatedly reading the first three transcripts. Next, they generated codes and themes independently from each other. Multiple meetings were devoted to cross-check the codes and the emerging themes. The remaining transcripts were then analysed by the interviewer, followed by random checks by the team members. Finally, the resulting framework and related quotes were sent back to three participants for cross-checking and collecting their feedbacks.

During the analysis, the team members mainly focused on the experiences of the participants with diagnosing SwD in their child, but they were also open to any new themes that emerged during the analysis process. Refining, testing and retesting of the emerging themes was undertaken until they achieved the best fit for the data. ${ }^{89}$ Data saturation was ensured when no extra relevant information emerged in the last interview. ${ }^{10}$ As data collection and analysis were performed simultaneously, the tenth interview did not produce any new area that required further exploration, accordingly data saturation was achieved.

Research reflexivity, as defined by Ahern, ${ }^{21}$ is the recognition of personal preconceptions and feelings and thinking critically about them in relation to the research being conducted. ${ }^{11}$ This was practiced by keeping a journal of the thoughts, feelings, and emotions to minimise researcher bias and improve the overall outcome.

All interviews were recorded using a Philips VoiceTracer (type: DVT6010, Korea). The transcription and analysis were carried out using Microsoft Word Office 2019.

\section{Patient and public involvement}

Patient and public were not involved in designing this study. However, they helped in triangulating the results.

\section{RESULT}

Saturation of ideas was achieved after interviewing ten parents. Four parents were referred to the multidisciplinary swallowing clinic by general paediatricians and six by emergency physicians. The median age of the children at diagnosis was 4.5 months (range of 1-23 months). They had been previously diagnosed with gastro-oesophageal reflux disease, asthma and/ or acute bronchiolitis. All of these children were diagnosed with SwD by FEES or VFSS and were managed by the multidisciplinary team using feeding modifications, injection laryngoplasty or endoscopic repairs of type one laryngeal clefts (table 1 ).
Table 1 Demographics of the participants

\begin{tabular}{|c|c|}
\hline \multicolumn{2}{|c|}{ Participant demographics } \\
\hline $\begin{array}{l}\text { No of interviewed } \\
\text { parents }\end{array}$ & 10 mothers \\
\hline Parental education & $\begin{array}{l}\text { Secondary school }(\mathrm{N}=1) \\
\text { Undergraduate degree }(\mathrm{N}=7) \\
\text { Postgraduate degree }(\mathrm{N}=2)\end{array}$ \\
\hline $\begin{array}{l}\text { Parents with a } \\
\text { health-related job }\end{array}$ & $\begin{array}{l}\text { Two of them: } \\
\text { Nursing } \\
\text { - Adult occupational therapist }\end{array}$ \\
\hline $\begin{array}{l}\text { Ethnicity of the } \\
\text { parents }\end{array}$ & $\begin{array}{l}\text { All of them were Canadian. } \\
\text { Arabic origin }(\mathrm{N}=1) \\
\text { African origin }(\mathrm{N}=2) \\
- \text { Caucasian }(\mathrm{N}=7)\end{array}$ \\
\hline No of children & 14 \\
\hline $\begin{array}{l}\text { Median diagnosis } \\
\text { age in months (IQR) }\end{array}$ & $4.5(6)$ \\
\hline $\begin{array}{l}\text { Male:female ratio of } \\
\text { the children }\end{array}$ & $6: 08$ \\
\hline
\end{tabular}

All families perceived that the diagnosis of SwD could have been reached or entertained earlier. They recounted many stories that demonstrated several elements leading to this belief. The three themes that emerged at the end of the analysis were: (1) fallacies or false beliefs about $\mathrm{SwD}$, (2) parent-related barriers and (3) healthcare-related barriers. Figure 1 shows the main themes.

\section{Fallacies about SwD}

The parents of OHITs expressed four erroneous beliefs related to $\mathrm{SwD}$. These beliefs were described as: (1) Cough is not a worrying symptom; (2) The presence of normal vital signs (ie, temperature, heart rate, respiratory rate, oxygen saturation) is reassuring; (3) Achieving proper milestones and gaining weight rule out a concerning health issue and (4) These infants and toddlers are still growing and acquiring their swallowing skills and pace. Interestingly, according to the parental reports, some of these beliefs were shared by some paediatricians. Table 2 contains examples of these erroneous beliefs.

\section{Parental-related barriers}

Barriers related to the parents were linked to two central ideas. They pertained to a lack of knowledge about $\mathrm{SwD}$ and the presence of psychosocial stressors affecting them. The presence of previous experience with the condition helped one parent to seek medical attention for her infant earlier than for the older child. However, most of the parents expressed a major burden of stress that affected their life quality and judgement. Table 3 shows excerpts of the parental accounts. 


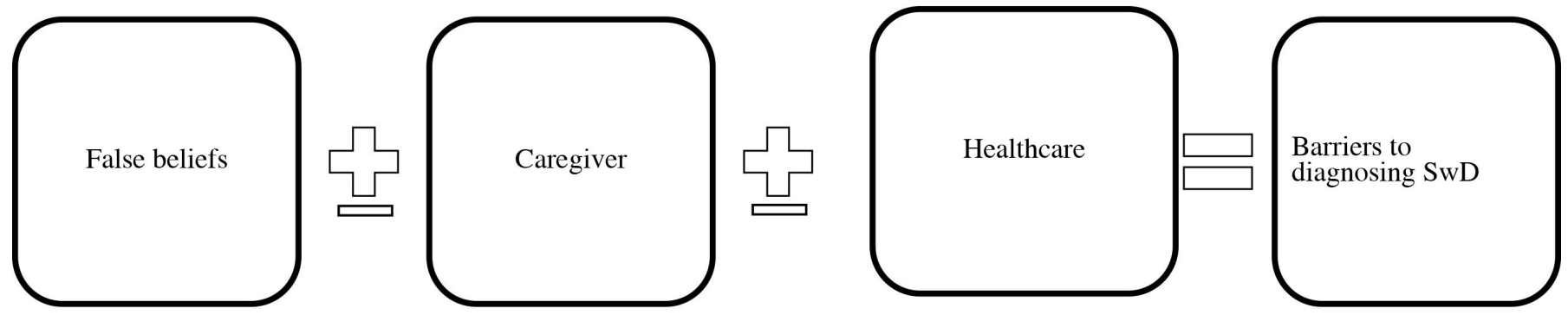

Figure 1 shows the barrier framework from emerging themes. It illustrates how intricate could be the impact of barriers on diagnosing swallowing dysfunction in the otherwise healthy cohort. These barriers could happen together in some cases or as a single theme to hinder the diagnosis. SwD, swallowing dysfunction.

\section{Healthcare-related barriers}

Healthcare-related barriers revolved around interacting with non-empathetic healthcare workers who would second guess or dismiss the parental reports or require proof of symptoms. As these hindrances prevented them from receiving care, parents of the affected OHITs were forced to improvise to convince the healthcare workers and obtain a referral to specialists. Some resorted to video and audio recording of the experiences to convince the healthcare professionals. Others educated themselves and tried different delivery systems to alleviate the symptoms (different types of nipples that control the flow). A selection of parental quotes are presented in table 4 .

\section{DISCUSSION}

This study provides insights about the barriers that hindered the diagnosis of SwD in OHITs, according to the parental reports. These barriers were streamlined and fitted into a model that has three themes, namely, fallacies about SwD in OHITs, parent-related barriers and clinician-related barriers. The study also demonstrates the complex interactions between the themes, where each

Table 2 Fallacies regarding SwD

\section{Theme 1: fallacies regarding SwD}

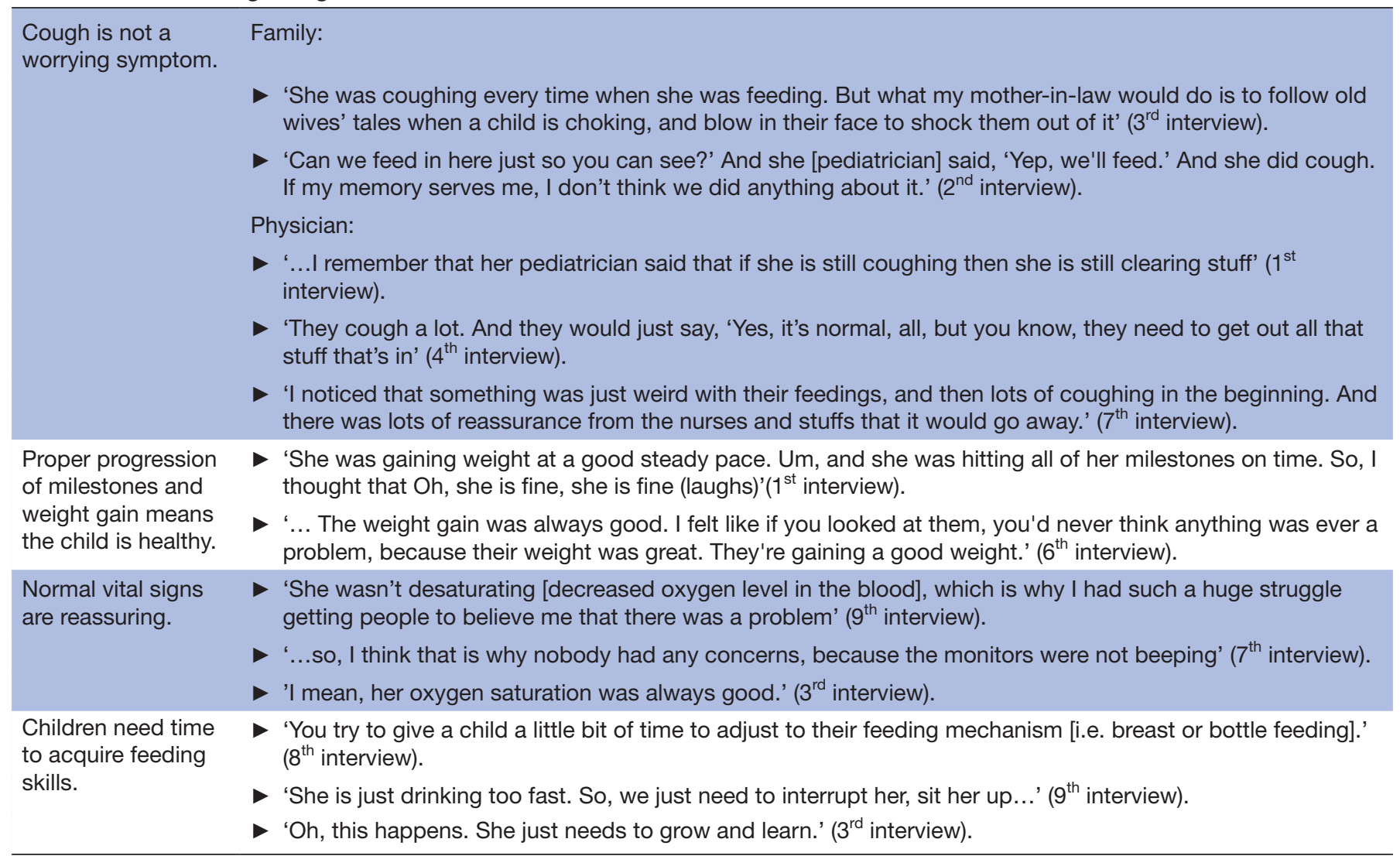

SwD, swallowing dysfunction. 
Table 3 Parent-related barriers

\section{Theme 2: parental barriers}

\begin{tabular}{|c|c|}
\hline $\begin{array}{l}\text { Lack of } \\
\text { education } \\
\text { or prior } \\
\text { experience }\end{array}$ & $\begin{array}{l}\text { 'What took so long was for us to figure out that something was actually going on with her and connecting the } \\
\text { dots that there could be a swallowing issue even though she was growing and gaining weight. And at most, } \\
\text { she would catch a cold or something, but the assumption was she just caught a cold because she has an } \\
\text { older brother going to school and coming home. And he would catch a cold and she would show symptoms. } \\
\text { It's hard to pinpoint what, um, what the cause was.' (6 } 6^{\text {th }} \text { interview). } \\
\text { 'I realized that maybe something was happening with her too. Yeah. It was a lack of knowledge' (3 } 3^{\text {rd }} \\
\text { interview). }\end{array}$ \\
\hline & $\begin{array}{l}\text { 'I wasn't working. I mean, with three kids. I mean, two were babies and they're both coughing and there was } \\
\text { just no sleep at all.' (5 } 5^{\text {th }} \text { interview). }\end{array}$ \\
\hline & $\begin{array}{l}\text { 'We were housebound everyone for two months. My son wasn't allowed to go to playgroup or school } \\
\text { anymore. I wouldn't go anywhere. When my husband came home, he wasn't allowed to touch her. I made } \\
\text { him take a shower, and I made him put on stupid hand sanitizer. I made people wear masks when they came } \\
\text { to my house because I didn't know what else to do.' (6 } 6^{\text {th }} \text { interview). }\end{array}$ \\
\hline
\end{tabular}

one acts as a barrier by itself or by amplifying one or more of the others in the model. For example, the healthcare provider may have erroneous beliefs that enforce those of the parent. Similarly, parental stress can weaken their stance and self-confidence and embolden an uninformed healthcare provider to ignore the complaints related to the child.

To our knowledge, this is the first report on the barriers to diagnosing SwD in this group of children. Most of the relevant available literature addresses the barriers or needs of parents of either older children ( $>2$ years), those with complex health problems (such as cerebral palsy) or both, ${ }^{22-25}$ and all of these studies were conducted in populations that already had a confirmed diagnosis.

Each part of our model contains distinct entities. Some of these entities are in agreement with previous reports, while others are unique to the current study. One of the previously reported entities is the fact that parents spotted the clinical presentations of the condition in their infants and toddlers. ${ }^{14}$ However, the parents did not have the ability to connect the dots and formulate a reason to seek an urgent medical consultation, which was also reported in Heweston and Singh's study. ${ }^{14}$ In the end, they believed it was a result of their insufficient understanding of SwD. ${ }^{1522} 24$

Parental beliefs about the condition were found to play a role in hindering SwD diagnosis. Mikhail interviewed 100 Hispanic women who had at least one child younger than 5 years to investigate beliefs about specific health etiologies (such as fever, cough and conjunctivitis). ${ }^{26}$ Eighty per cent of the interviewed parents believed that cough is caused by an imbalance between hot and cold environments. Traditional or home remedies (such as increased fluid intake, the use of a humidifier, and the application of a grounded coffee poultice on the soles of feet) were performed by $41 \%$ of the parents to manage the cough. ${ }^{26}$

\section{Table 4 Healthcare-related barriers}

\section{Theme 3: healthcare personnel-related barriers}

Healthcare providers ignore what parents say and do not consider SwD.

The physician agrees to refer only after the problem is demonstrated or witnessed.
- 'Well, I just got dismissed. Like I seriously went through three pediatricians and, uh, the last one that I went to that did the referral, she was dismissive of me as well.' ( $3^{\text {rd }}$ interview).

- 'I will vent about it. Like my biggest peeve with our medical system is a dismissive attitude towards either a mom or a nurse who knows better than a doctor. It is a problem.' ( $2^{\text {nd }}$ interview).

- 'I said 'If you give me a chance, I will prove it to you.' She said 'Okay.' She was like 'how are you planning on proving it?' I said well, I have three different flows and fluid consistencies. I want you to watch her drinking. I will start with the slowest flow with the thickest consistency, and you tell me. I had a nectar thick mango juice through the slow flow bottle. She watched what was happening. She was like 'yeah, she needs swallowing assessments.' ( $1^{\text {st }}$ interview).

- 'Anyway, so it was tough. It was tough getting that referral. It was tough trying to speak to the pediatrician about all these symptoms.' (9th interview).

- 'It was actually that night, I went to the emergency at the Stollery Children's Hospital and I said I am at my wit's end. I am not sleeping. I do not know what to do. So, it was actually, I believe if my memory serves me, the emergency that referred us.' (2nd interview). 
In our study, parents reported that coughing or choking was addressed by startling the infant or by changing the feeding position. These practices could be explained by a lack of education and not having previous experience with SwD, as reported by most of our interviewed parents. This lack of knowledge drove parents to proactively seek out information either through searching for answers from other sources or through a trial and error approach, as demonstrated in this work and by others. ${ }^{14} 15222427$

The parents consulted healthcare professionals only after they had gone through a 'wait and see' period and used all advice from close family and friends. Some reports described parents thinking that healthcare professionals were "in over their heads' or 'did not seem to know a lot about it.' 142 Some parents consulted several physicians without receiving a convincing or good explanation for the problem. ${ }^{22}$ In our study, the healthcare professionals expressed erroneous beliefs to the parents or provided baseless reassurance to them, as reported by the parents. ${ }^{14}$ Therefore, there is a pressing need to educate parents and primary healthcare workers about the prevalence, presentation, and management of SwD.

Anxiety and psychosocial stress were reported by most of the participants. This could be explained by the parental uncertainty of diagnosis, by dealing with day-to-day feeding and swallowing issues, and by the difficulties encountered to access information (ie, difficulty in obtaining information or receiving insufficient or inaccurate advice). ${ }^{22} 242528 \mathrm{In}$ addition, lack of sleep and limited personal time could have amplified parental anxiety and stress. One of the parents whom we interviewed frankly stated '...no sleep at all,' which was also reported in the Estrem et al study. ${ }^{29}$ Some parents thought they neglected their own health to mitigate the dayto-day swallowing issues and to coordinate hospital visits and referrals. ${ }^{28}$ It appears that acknowledging their strain and efforts and providing these parents with support is urgently needed.

The presence of an OHIT with SwD changed the family dynamic from several points of view. First, it restricted the family freedom to eat outside the home, as found by Estrem et al. ${ }^{29}$ We found that it restricted family leisure time either by limiting their pursuit of hobbies or preventing travelling or social interaction during holidays. ${ }^{14}{ }^{15}$ These changes complicated the family dynamics and made the parents further prone to developing conflicts in their relationships and also contributed to health deterioration; ${ }^{14}{ }^{15}$ these circumstances might indirectly impact the child's health.

Parents reported that a negative or dismissive attitude of healthcare professionals was one of the contributors to their stress. In Cowpe et al one parent reported that 'More the medical side than the community side have no respect for what the parents have to say... it is quite nice when you find people who actually listen. ${ }^{, 2}$ Being dismissed was one of the findings of the current report and has also been reported in other studies. ${ }^{14}{ }^{15}$ Parents are happy to work and learn together with a healthcare professional who has the ability to admit a scarcity of knowledge about the condition. ${ }^{23}{ }^{30}$ If the healthcare worker is not comfortable managing the case, providing access to specialist care would greatly help the parents.

Finally, we would like to further discuss the interviews that were conducted over the course of our study. A couple of the parents broke down and wept. They recounted their stories of helping other families who were in the same situation. They also expressed that they would do anything possible to prevent seeing others from going down the same path. ${ }^{29}$ One of the parents began to post daily information on social media about her infant in an effort to motivate her followers and friends to read about the condition. Collaboration between the care providers and families is needed to address this condition and improve the provided care.

The present study has some limitations. Due to the nature of the qualitative approach, the results cannot be completely generalised, although all of the participants expressed a struggle in one or more domains of the model. A quantitative study to assess this framework and its validity is needed. Additionally, this framework was based on the insight of parents without incorporating the opinions of the healthcare professionals, which would likely further characterise the phenomena. The purposeful sampling of the participants provided rich information about the experiences of families. However, these parents already had access to a specialty clinic or had begun a management plan, and we did not consider sociodemographic differences. Including caregivers of the affected children from the community may have provided a different dimension. Lastly, we have limited our conclusions to the cohort of interest (OHITs diagnosed with $\mathrm{SwD}$ ), but we cannot confirm that these barriers are specific to them.

To conclude, there are multidimensional barriers to achieving a diagnosis of SwD in OHITs. These barriers are erroneous beliefs about SwD, parent-related barriers and clinician-related barriers. A critical factor that might enhance the presence of these barriers is a lack of knowledge and education about SwD in the general population and in community healthcare workers. Further research is required to assess these barriers and to verify their impact on the management of this condition.

Twitter Hamdy El-Hakim @asrarelhakim

Acknowledgements We would like to present our thanks to the parents who were willing to discuss their story to put a groundwork for this study. Also, we would like to dedicate this study to the soul of our SLP, Wendy Johannsen, for her great work and efforts as she passed away before this work comes to the light.

Contributors $\mathrm{AB}$ : concept and design, data collection, data interpretation, drafting the manuscript, and final approval. MR: data collection, data interpretation, drafting the manuscript and final approval. WJ: data collection, drafting the manuscript and final approval. HS: concept and design, data collection and final approval. HE-H: concept and design, data collection, data interpretation, drafting the manuscript and final approval.

Funding The authors have not declared a specific grant for this research from any funding agency in the public, commercial or not-for-profit sectors.

Competing interests None declared.

Patient consent for publication Not required.

Ethics approval This study employed a descriptive qualitative approach. It was approved by the University of Alberta Ethics Board (Pro00073985) and was undertaken at the Stollery Children's Hospital, Edmonton, Alberta, Canada.

Provenance and peer review Not commissioned; externally peer reviewed. 
Data availability statement All data relevant to the study are included in the article or uploaded as online supplemental information.

Supplemental material This content has been supplied by the author(s). It has not been vetted by BMJ Publishing Group Limited (BMJ) and may not have been peer-reviewed. Any opinions or recommendations discussed are solely those of the author(s) and are not endorsed by BMJ. BMJ disclaims all liability and responsibility arising from any reliance placed on the content. Where the content includes any translated material, BMJ does not warrant the accuracy and reliability of the translations (including but not limited to local regulations, clinical guidelines, terminology, drug names and drug dosages), and is not responsible for any error and/or omissions arising from translation and adaptation or otherwise.

Open access This is an open access article distributed in accordance with the Creative Commons Attribution Non Commercial (CC BY-NC 4.0) license, which permits others to distribute, remix, adapt, build upon this work non-commercially, and license their derivative works on different terms, provided the original work is properly cited, appropriate credit is given, any changes made indicated, and the use is non-commercial. See: http://creativecommons.org/licenses/by-nc/4.0/.

ORCID iD

Abdulsalam Baqays http://orcid.org/0000-0002-7223-4880

\section{REFERENCES}

1 Bhattacharyya N. The prevalence of pediatric voice and swallowing problems in the United States. Laryngoscope 2015;125:746-50.

2 Benfer KA, Weir KA, Bell KL, et al. Longitudinal cohort protocol study of oropharyngeal dysphagia: relationships to gross motor attainment, growth and nutritional status in preschool children with cerebral palsy. BMJ Open 2012;2 doi:10.1136/bmjopen-2012-001460

3 Benfer KA, Weir KA, Bell KL, et al. Oropharyngeal dysphagia in children with cerebral palsy: comparisons between a high- and lowresource country. Disabil Rehabil 2017;39:2404-12.

4 Mercado-Deane MG, Burton EM, Harlow SA, et al. Swallowing dysfunction in infants less than 1 year of age. Pediatr Radiol 2001;31:423-8.

5 Sheikh S, Allen E, Shell R, et al. Chronic aspiration without gastroesophageal reflux as a cause of chronic respiratory symptoms in neurologically normal infants. Chest 2001;120:1190-5.

6 Lefton-Greif MA, Carroll JL, Loughlin GM. Long-term follow-up of oropharyngeal dysphagia in children without apparent risk factors. Pediatr Pulmonol 2006;41:1040-8.

7 Svystun O, Johannsen W, Persad R, et al. Dysphagia in healthy children: characteristics and management of a consecutive cohort at a tertiary centre. Int J Pediatr Otorhinolaryngol 2017;99:54-9.

8 Casazza G, Graham M, Asfour F, et al. Aspiration in the otherwise healthy Infant-Is there a natural course for improvement? Laryngoscope 2019.

9 Arvedson JC. Assessment of pediatric dysphagia and feeding disorders: clinical and instrumental approaches. Dev Disabil Res Rev 2008;14:118-27.

10 Brady S, Donzelli J. The modified barium swallow and the functional endoscopic evaluation of swallowing. Otolaryngol Clin North Am 2013;46:1009-22.

11 Little MP, Wakeford R, Borrego D, et al. Leukaemia and myeloid malignancy among people exposed to low doses ( $<100 \mathrm{mSv})$ of ionising radiation during childhood: a pooled analysis of nine historical cohort studies. Lancet Haematol 2018;5:E346-58.

12 Allik H, Larsson J-O, Smedje H. Guidance for industry: patientreported outcome measures: use in medical product development to support labeling claims: draft guidance. Health Qual Life Outcomes 2006;4:1-20. doi:10.1186/1477-7525-4-1

13 Tubach F, Ravaud P, Baron G, et al. Evaluation of clinically relevant changes in patient reported outcomes in knee and hip osteoarthritis: the minimal clinically important improvement. Ann Rheum Dis 2005;64:29-33.

14 Hewetson R, Singh S. The lived experience of mothers of children with chronic feeding and/or swallowing difficulties. Dysphagia 2009;24:322-32.

15 Lutz KF. Feeding problems of neonatal intensive care unit and pediatric intensive care unit graduates: perceptions of parents and providers. Newborn Infant Nurs Rev 2012;12:207-13. doi:10.1053/j. nainr.2012.09.008

16 Lewis E, Kritzinger A. Parental experiences of feeding problems in their infants with Down syndrome. Downs Syndr Res Pract 2004;9:45-52.

17 Nelson KE, Lacombe-Duncan A, Cohen E, et al. Family experiences with feeding tubes in neurologic impairment: a systematic review. Pediatrics 2015;136:e140-51.

18 Glasser B, Strauss A. The development of grounded theory. Chicago: Alden, 1967.

19 Starks H, Trinidad SB, Brown Trinidad S. Choose your method: a comparison of phenomenology, discourse analysis, and grounded theory. Qual Health Res 2007;17:1372-80.

20 Braun V, Clarke V, Hayfield N, et al. Thematic analysis. Handbook of research methods in health social sciences, 2019: 843-60.

21 Ahern KJ. Ten tips for reflexive bracketing. Qual Health Res 1999;9:407-11. doi:10.1177/104973239900900309

22 Cowpe Jebson E, Hanson B, Smith $\mathrm{CH}$. What do parents of children with dysphagia think about their MDT? A qualitative study. BMJ Open 2014;4:e005934.

23 Angell ME, Bailey RL, Stoner JB. Family perceptions of facilitators and inhibitors of effective school-based dysphagia management. Lang Speech Hear Serv Sch 2008;39:214-26. doi:10.1044/01611461

24 Fisher HR. The needs of parents with chronically sick children: a literature review. J Adv Nurs 2001;36:600-7.

25 Stoner JB, Bailey RL, Angell ME, et al. Perspectives of parents/ guardians of children with feeding/swallowing problems. J Dev Phys Disabil 2006;18:333-53.

26 Mikhail BI. Hispanic mothers' beliefs and practices regarding selected children's health problems. West $J$ Nurs Res 1994;16:623-38.

27 Cohen $\mathrm{MH}$. The unknown and the unknowable-managing sustained uncertainty. West J Nurs Res 1993;15:77-96.

28 Holm KE, Patterson JM, Rueter MA, et al. Impact of uncertainty associated with a child's chronic health condition on parents' health. Fam Syst Health 2008;26:282-95.

29 Estrem HH, Thoyre SM, Knafl KA, et al. 'It's a long-term process': description of daily family life when a child has a feeding disorder. $J$ Pediatr Health Care 2018;32:340-7.

30 Garro A, Thurman SK, Kerwin ME, et al. Parent/caregiver stress during pediatric hospitalization for chronic feeding problems. J Pediatr Nurs 2005;20:268-75. 